\title{
In recognition of Ireland's doctor scientists: Richard Costello, Christopher Thompson, Fidelma Dunne and Douglas Veale
}

\author{
William P. Tormey ${ }^{1,2,3,4}$ \\ Published online: 25 April 2018 \\ (C) Royal Academy of Medicine in Ireland 2018
}

\begin{abstract}
A clinician scientist for the long haul is relatively unusual in medicine. The difficulty journal editors have in getting professionals to review papers which may take four or more hours is a fact of modern academic publishing. There is no financial incentive to participate. Professionalism as a subject is part of formal basic medical training in this era. This has replaced some of the clinical clerkship and apprenticeship time periods of pre-modern medical training. During my undergraduate period in UCD 1968-1974, 'The Clinical Apprentice' and 'A Primer of Medicine' were the prototype general textbooks for medical students of that era $[1,2]$. The transformation in learning methods and evaluations can be gauged by my recent review [3].
\end{abstract}

\section{Professor Richard Costello}

Richard Costello graduated in the top 1\% of his class, at RCSI Dublin in 1988. He trained in the Pulmonary and Critical Care Fellowship program at The Johns Hopkins Hospital, Baltimore, USA, from 1993 to 1997. In 2000, he earned an MD doctorate from UCD. Following this, he was appointed Senior Lecturer in Peter Calverely's Department at the University of Liverpool. He moved back to RCSI in 2000 as a Consultant Physician and Senior Lecturer and has been promoted through the academic ranks.

Professionally, from a clinical point of view, he is active in inpatient and outpatient general respiratory and internal

William P. Tormey

billtormey@gmail.com

1 Department of Chemical Pathology, Beaumont Hospital, Dublin, Ireland

2 Biomedical Sciences, Ulster University, Coleraine, UK

3 Medical School, Trinity College Dublin, Dublin, Ireland

4 Health Sciences, Athlone Institute of Technology, Westmeath, Ireland medicine. He leads national specialist clinics in severe asthma and is the clinical lead for the National Severe Asthma programme. He also runs specialist sleep and ventilation and is Past President of the Irish Sleep Society.

Educationally, he served as the National Specialist Director of Training in Ireland in respiratory medicine from 2002 to 2012, developing a structured training programme, a curriculum and an assessment process. He now leads the well-funded research in medical education department at the Royal College of Physicians of Ireland. He is President of the European Board of Pulmonology, Board Member of the ERS HERMES respiratory exam group, Board Member of the ERS Education council and Board Member of the Asthma Society.

Academically, he is a Health Research Board of Ireland Clinician Scientist. In the last 10 years, he has led a multidisciplinary group of academics studying how technology can be used to optimise adherence to therapy and improve outcomes in patients with respiratory disease. He has developed and copyrighted technology related to assessment of inhaler adherence. He holds two patents on the use of audio analysis for respiratory monitoring and estimation of adherence. The INCA technology is licenced to an indigenous Irish company Vitalograph. He has trademarked a FDA-approved process for trage of patients with severe asthma. He has published over 112 original research papers in respiratory medicine. His work is currently supported by grants of over $€ 5 \mathrm{~m}$ from the EU, industry partners and the Health Research Board of Ireland. He has supervised 15 $\mathrm{MD}$ and $10 \mathrm{PhD}$ students. His h-index is 31 with $>3290$ citations, and his i10 index is 47 .

\section{References}

1. Hunt E, Flynn D, MacHale E, Costello RW, Murphy DM. Reduction in exhaled nitric oxide tracks improved patient compliance in difficult asthma-a case 
study. J Asthma 2017; 26:1-3. https://doi.org/10. 1080/02770903.2017.1414237.

2. Cushan B, Sulaiman I, Greene G, et al. Clinical outcomes of poor adherence in COPD. Am J Resp Crit Care Med 2018 in press.

\section{Professor Christopher J Thompson}

Professor Thompson attended St Cuthbert's Catholic High School at Hadrian's Wall, Newcastle, on Tyne, England. He qualified from Dundee University in Medicine in 1981 and trained in Endocrinology in Newcastle upon Tyne, where he was awarded his MD thesis. He worked as a Lecturer in Medicine in Edinburgh University, from where he was funded to work as Associate Professor in the Department of Physiology, University of California at San Francisco. $\mathrm{He}$ returned to Scotland as Consultant Endocrinologist in Glasgow before taking up post at Beaumont Hospital in 1997. He has Fellowship of the Royal College of Physicians of Ireland and Edinburgh.

He has served as Chairman of Diabetes Ireland and secretary of the Irish Endocrine Society. He is chairman of the European Hyponatraemia Network and was the European delegate on the world consensus guidelines for management of hyponatraemia, published in 2013. $\mathrm{He}$ has served on the medical and scientific committee of the GAA and is doctor to the Dublin Hurling Team.

His areas of interest include pituitary disease, adrenal disease, hyponatraemia, diabetes insipidus, sports endocrinology, sports and diabetes. He has published extensively on hyponatraemia, pituitary tumours, diabetes insipidus - SIADH, thyroid disease and pituitary disease following brain injury.

\section{References}

1. Serban Radian, Yoan Diekmann, Plamena Gabrovska, et al. 2017. Increased population risk of AIP-related acromegaly and gigantism in Ireland. Hum Mutat. Jan; 38(1): 78-85. Published online 2016 Oct 4 . https://doi.org/10.1002/humu. 23121

2. Michael W O'Reilly, Raoul C. Reulen, Saket Gupta, et al. $\mathrm{ACTH}$ and gonadotropin deficiencies predict mortality in patients treated for nonfunctioning pituitary adenoma: long-term follow-up of 519 patients in two large European centres. Clin Endocrinol 2016 Nov; 85(5): 748-756. https://doi.org/10.1111/cen.13141

\section{Professor Fidelma Dunne}

Fidelma Dunne holds a Personal Professorship in Medicine and is currently Head of the School of Medicine at the National University of Ireland. She is a Consultant Endocrinologist at Galway University Hospitals. She obtained her medical degree from the National University of Ireland Galway (NUIG), her MD from University College Cork, her $\mathrm{PhD}$ from the University of Birmingham, UK, and also holds a Masters in Medical Education from the University of Dundee, Scotland. On Google Scholar, her h-index is 36, her i10 index is 85 and citations are 5188 by April 2018. In 2014, she was awarded a Fulbright Scholar Award and is a research partner with Professor Mary Dalton of Columbia University, New York City.

Her major research interest is in the area of pregnancy and diabetes. Her research group is currently conducting a number of studies as part of the ATLANTIC DIP programme. These studies are focusing on pregnancy outcomes in women with type 1 and type 2 diabetes.

In addition, she is involved in a multicentre Europeanfunded FP7 programme on prevention of gestational diabetes mellitus (DALI) using vitamin D and lifestyle intervention; CONCEPTT, a JDRF-funded programme examining the benefits of CGMS in women with type 1 diabetes during pregnancy; and EVOLVE, a pan European collection of outcomes for women with type 1 and type 2 diabetes treated with insulin.

Professor Dunne is the only Irish committee member of the Diabetes in Pregnancy Study Group (EASD) of EASD and is the President of the International Diabetes in Pregnancy Study Groups (IADPSG) from 2016 to 2021. She is a member of the research committee of the International Federation of Gynecology and Obstetrics (FIGO).

Professor Dunne is actively involved in undergraduate and postgraduate education through the College of Medicine Nursing and Health Sciences at the National University of Ireland, Galway (NUIG) and at the Royal College of Physicians (RCPI).

\section{References}

1. McIntyre D, Desoye G, Dunne F, et al. FIGO analysis of research priorities in hyperglycemia in pregnancyDiabetes Res Clin Pract 2018 Mar 26 pii: S0168-8227(18)30106-2. https://doi.org/10.1016/jdiabres201803.026.

2. Broekhuizen K, Simmons D, Devlieger R, et al. Costeffectiveness of healthy eating and/or physical activity promotion in pregnant women at increased risk of gestational diabetes mellitus: economic evaluation alongside the DALI study, a European multicenter randomized controlled trial. Int J Behav Nutr Phys Act. 2018 Mar 14; 15(1):23. https://doi.org/10.1186/s12966-018-0643-y. 


\section{Professor Douglas Veale}

Douglas J. Veale is the Director of Translational Research of the Dublin Academic Medical Centre, Professor of Medicine and Consultant Rheumatologist at St Vincent's University Hospital and a Principal Investigator at The Conway Institute for Biomedical and Biomolecular Research, University College Dublin (UCD). He is a fellow of both the Royal College of Physicians in Ireland (1997) and the Royal College, London (1999). Professor Veale graduated from the Royal College of Surgeons in Ireland in 1984 and obtained his MD by thesis from UCD in 1992.

Professor Veale has established an international reputation in translational research in the areas of angiogenesis, early arthritis, biopharmaceutical therapy, biomarkers and scleroderma. He has established an excellent research team including senior scientists, post-doctoral scientists, clinical research fellows and $\mathrm{PhD}$ students funded by peer-reviewed grants from the American Federation for Ageing Research, the European Union FP6 programme and Innovative Medicines Initiative (IMI), Health Research Board of Ireland, Science Foundation Ireland, the Programme for Research in Third Level Institutions and several industry partnership programmes for research with Pfizer, Jannsen and Roche.

The Translational Research programme integrates immunology research across groups - colorectal, endocrine, hepatic and rheumatology in the ERC, the Conway Institute, UCD and TCD. The primary clinical focus is on inflammatory arthritis and scientifically on hypoxia, angiogenesis and inflammation. In 2012, Professor Veale was elected to the Editorial
Board of Annals of Rheumatic Disease (Impact Factor 9111) and Rheumatology, and the EULAR Scientific Committee. $\mathrm{He}$ is a section chair and leads an abstract selection committee for the American College of Rheumatology. His Google Scholar data include a h-index of 63, i10 of 184 and total citations of 14,654.

\section{References}

1. McGarry T, Biniecka M, Veale D, Fearon U. Hypoxia, oxidative stress and inflammation.U Free Radic Biol Med. 2018 Mar 27. pii: S0891-5849(18)30145-X. https://doi.org/10.1016/j.freeradbiomed.2018.03.042.

2. Orr C, Vieira-Sousa E, Boyle DL at al. Corrigendum: synovial tissue research: a state-of-the-art review. Nat Rev Rheumatol. 2017 Dec 19;14(1):60. https://doi.org/ 10.1038/nrrheum.2017.206.

\section{References}

1. Naish JM, Read AEA (1966) The clinical apprentice. A handbook of bedside methods, 3rd edn. John Wright, Bristol

2. Pappworth MH (1971) A primer of medicine. In: Eliciting and assessing clinical signs, and the art and science of diagnosis, 3rd edn. Butterworth and co., London

3. Tormey W (2015) Education, learning and assessment: current trends and best practice for medical educators. Ir J Med Sci 184(1):1-12. https://doi.org/10.1007/s11845-014-1069-4 